\title{
Efeito do Tratamento Térmico de Solubilização e Estabilização Convencional e Alternativo na Microestrutura de uma Junta Soldada com Aço Inox 347
}

Renata Barbosa Gonçalves ${ }^{1}$, Pedro Henrique Dias de Araújo ${ }^{1}$, Flávio José Villela Braga² ${ }^{2}$ Luis Augusto Hernandez Terrones ${ }^{3}$, Ronaldo Pinheiro da Rocha Paranhos ${ }^{3}$

1 Departamento de Engenharia e Ciência dos Materiais, Universidade Estadual do Norte Fluminense - UENF, Campos dos Goytacazes, RJ, Brasil.

2 Schulz Tubos Soldados Ltda, Campos dos Goytacazes, RJ, Brasil.

3 Laboratório de Materiais Avançados - LAMAV, Centro de Ciência e Tecnologia - CCT, Universidade Estadual do Norte Fluminense - UENF, Campos dos Goytacazes, RJ, Brasil.

Recebido: 20 Ago., 2014

Aceito: 07 Abr., 2015

E-mails:

lucho@uenf.br(LAHT), paranhos@ uenf.br (RPRP)
Este é um artigo publicado em acesso aberto (Open Access) sob a licença Creative Commons Attribution Non-Commercia que permite uso, distribuição e reproduçăo em qualq'uer meio, sem restriç̄oes desde que sem fins comerciais eque 0 trabalho original seja corretamente citado.
Resumo: Este trabalho estuda a microestrutura formada na zona termicamente afetada (ZTA) e na zona fundida (ZF) de uma junta soldada pelo processo TIG automático no passe de raiz, processo plasma nos passes de enchimento e soldagem SAW para os passes de acabamento em junta de topo com chanfro " $V$ " simples, usando o aço inoxidável austenítico AISI 347. Foram estudadas as condições: como soldada; após tratamento térmico convencional de solubilização a $1060{ }^{\circ} \mathrm{C}$ e estabilização a $900{ }^{\circ} \mathrm{C}$; e após tratamento térmico alternativo, onde a peça foi solubilizada a $1060^{\circ} \mathrm{C}$ e mantida no forno que foi resfriado até $900{ }^{\circ} \mathrm{C}$ para a estabilização. Os resultados mostram que, na condição como soldado houve crescimento de grão na ZTA e a ZF apresentou $13 \%$ de ferrita $\delta$ com diferentes morfologias, tendo sido observada a precipitação de carbetos de $\mathrm{Cr}$ e de $\mathrm{Nb}$. Após o tratamento térmico convencional de solubilização e estabilização, foi observada uma diminuição significativa do teor de ferrita $\delta$ na ZTA e na ZF, tendo sido observados carbetos de $\mathrm{Nb}$ e $\mathrm{Cr}$, distribuídos de forma mais dispersa e com tamanhos menores, que contribuem para minimizar a possibilidade de ocorrer o fenômeno da sensitização. Após tratamento térmico alternativo de solubilização e estabilização, a microestrutura da ZTA e ZF foi similar à obtida no tratamento convencional, sendo que o teor de ferrita $\delta$ na ZF foi ainda mais reduzido, de $4,5 \%$. Foi concluído que o tratamento térmico alternativo de solubilização e estabilização foi tão eficaz quanto o tratamento térmico convencional para a adequação da microestrutura da junta soldada, com uma significativa vantagem do tratamento térmico proposto em reduzir o tempo e o custo desta operação.

Palavras-chave: Aço inox 347; Soldagem; Tratamento térmico; Solubilização; Estabilização; Microestrutura.

\section{Effect of Conventional and Alternative Solubilization and Stabilization Heat Treatment on Microstructure of a 347 Stainless Steel Welded Joint}

\begin{abstract}
This work studies the microstructure formed in the heat affected zone (HAZ) and the melted zone (MZ) of a joint welded by automatic TIG in the root bead, plasma in the filling and SAW in the finish beads in a single $\mathrm{V}$ groove joint, using austenitic stainless steel AISI 347. The following conditions were studied: as welded; after conventional heat treatment of solubilisation at $1060{ }^{\circ} \mathrm{C}$ and stabilization at $900{ }^{\circ} \mathrm{C}$; and after alternative heat treatment, where the piece was solubilized at $1060^{\circ} \mathrm{C}$ and kept in the oven which was cooled up to $900^{\circ} \mathrm{C}$ for stabilization. The results show that, in the as welded condition, there was grain growth in the $\mathrm{HAZ}$ and the $\mathrm{MZ}$ shows $13 \%$ of $\delta$ ferrite with different morphologies, and the precipitation of $\mathrm{Nb}$ carbides and $\mathrm{Cr}$ carbides. After the conventional solubilisation and stabilization heat treatment, it was observed a significant reduction on $\delta$ ferrite content both in HAZ and $M Z$, and $\mathrm{Nb} \mathrm{Cr}$ carbides have been observed dispersed and distributed more with smaller sizes, which contribute to minimize the possibility of the phenomenon of sensitization. After the alternative heat treatment of solubilisation and stabilization, the microstructure of both $\mathrm{HAZ}$ and $\mathrm{MZ}$ was similar to the obtained with the conventional heat treatment, with the $\delta$ ferrite content in $\mathrm{MZ}$ was further reduced to $4.5 \%$. It was concluded that the alternative heat treatment of solubilisation and stabilization was so effective as the conventional heat treatment for adjusting the microstructure of the welded joint, with a significant advantage of the proposed heat-treatment to reduce the time and cost of the this operation.
\end{abstract}

Key-words: Stainless steel 347; Welding; Heat treatment; Solubilisation; Stabilization; Microstructure. 


\section{Introdução}

Os aços inoxidáveis austeníticos estabilizados, AISI 347e AISI 321, são resistentes à sensitização e à corrosão intergranular devido à presença de carbetos estabilizantes de $\mathrm{Nb}$ ou Ti, que previnem a precipitação de carbetos de Cr. Para tal, são submetidos aos tratamentos térmicos de solubilização e estabilização [1].

Estes aços quando soldados apresentam aumento significativo no teor de ferrita delta $(\delta)$, além da possibilidade de precipitação de fases deletérias como carbetos de $\mathrm{Cr}$. A literatura [2] recomenda um teor mínimo de ferrita $\delta$ no metal de solda austenítico para se evitar trincas a quente, já que essa fase dissolve elementos formadores de eutéticos de baixo ponto de fusão. Já a precipitação de carbetos de $\mathrm{Cr}$ decorrente da soldagem diminui o teor de $\mathrm{Cr}$ nas adjacências dos contornos de grão, caracterizando a sensitização, responsável pela corrosão intergranular [3], podendo também haver diminuição da ductilidade e tenacidade [4] conforme a morfologia e quantidade de precipitados na microestrutura.

O tratamento térmico de solubilização pode eliminar a precipitação de fases que surgem devido ao ciclo térmico de soldagem ao qual a junta soldada é submetida, recuperando as propriedades mecânicas. Grande parte dos precipitados formados durante a solidificação é dissolvida, mantendo os elementos de liga em solução sólida na matriz austenítica [5,6]. $O$ tratamento de estabilização após a solubilização faz que o $\mathrm{C}$ reaja preferencialmente com os elementos estabilizadores formadores de carbetos: $\mathrm{Nb}$, Ti ou $\mathrm{V}$, com os quais o $\mathrm{C}$ tem maior afinidade que o $\mathrm{Cr}$ no patamar de temperatura do tratamento. Assim, o teor de $\mathrm{C}$ livre na estrutura é reduzido, prevenindo o aço do fenômeno de sensitização [7].

O objetivo deste trabalho foi estudar uma junta soldada com o aço inoxidável austenítico AISI 347 em três condições: como soldado; após tratamento térmico convencional de solubilização e estabilização, conforme a norma A 358 [8], com saída da peça do forno e resfriamento até a temperatura ambiente após a solubilização e em seguida aquecido novamente para a estabilização; e em uma condição de tratamento térmico alternativo, onde a peça após a solubilização permaneceu no forno, que foi resfriado até o patamar do tratamento térmico de estabilização, sendo então resfriado até a temperatura ambiente. $O$ estudo foi realizado por meio da caracterização e comparação das microestruturas, incluindo a quantidade e tipos de precipitados observados (ferrita $\delta$ e tipos de carbetos).

\section{Materiais e Métodos}

A Tabela 1 mostra a composição da chapa de aço inox 347 de dimensões $12,7 \times 780 \times 6000 \mathrm{~mm}$ e do arame ER347Si. A solda foi do tipo junta de topo com chanfro em "V". A chapa foi soldada pelo processo solda plasma (PAW) no passe de raiz com gás de purga de 99,996\% Argônio, arame ER347Si de diâmetro 1,2 mm, com parâmetros $260 \mathrm{~A}, 32 \mathrm{~V}$ e velocidade de $15 \mathrm{~cm} / \mathrm{min}$, seguido de passe com processo TIG (GTAW) automático com adição de arame ER347Si de diâmetro $1,2 \mathrm{~mm}$, com parâmetros $240 \mathrm{~A}, 19 \mathrm{~V}$ e velocidade de $22 \mathrm{~cm} / \mathrm{min}$. Por ultimo, soldado pelo processo arco submerso (SAW) para enchimento do chanfro interno usando um fluxo básico-neutro, arame ER347Si de diâmetro $3,2 \mathrm{~mm}$, com parâmetros $440 \mathrm{~A}, 30 \mathrm{~V}$ e velocidade de $45 \mathrm{~cm} / \mathrm{min}$.

Na condição de tratamento térmico convencional, conforme a norma A358 [8], a solubilização foi feita inserindo a peça no forno a $800^{\circ} \mathrm{C}$, elevando a temperatura até $1040^{\circ} \mathrm{C}$, permanecendo nesta por $60 \mathrm{~min}$., seguido de resfriamento em água até a temperatura ambiente. A seguir, o tratamento térmico de estabilização, a peça foi introduzida no forno à temperatura de $750^{\circ} \mathrm{C}$, em seguida elevado até $900^{\circ} \mathrm{C}$, permanecendo nesta temperatura por 90 min., seguido de resfriamento ao ar até a temperatura ambiente.

$\mathrm{Na}$ condição de tratamento térmico alternativo, a solubilização seguida da estabilização foi realizada em uma única passagem pelo forno, de forma não convencional. A peça foi colocada dentro do forno a uma temperatura de $800^{\circ} \mathrm{C}$ que foi elevado a $1040^{\circ} \mathrm{C}$ permanecendo por $60 \mathrm{~min}$. e, em seguida, com o forno fechado, a temperatura

Tabela 1. Composição química da chapa de aço e do arame de solda.

\begin{tabular}{lcccccccccc}
\hline & C\% & Mn\% & Si\% & P\% & S\% & Cr\% & Ni\% & Mo\% & Al\% & Nb\% \\
Aço AISI 347 & 0,042 & 1,91 & 0,45 & 0,027 & 0,001 & 17,39 & 9,00 & 0,021 & 0,0032 & 0,486 \\
Arame ER347Si & 0,038 & 1,41 & 0,80 & 0,021 & 0,014 & 19,24 & 9,76 & 0,22 & 0,003 & 0,66 \\
\hline
\end{tabular}


foi reduzida até o patamar de $900{ }^{\circ} \mathrm{C}$, permanecendo neste por 90 min., e seguido de resfriamento ao ar até a temperatura ambiente.

Para observação da microestrutura, as amostras foram retiradas de cortes transversais ao cordão de solda, lixadas, polidas, sendo submetidas a ataque eletrolítico com tensão de $2 \mathrm{~V}$ e corrente de 1,2 A em solução de ácido oxálico 10\% por cerca de 90 s. Foram observadas a zona fundida (ZF), a zona termicamente afetada (ZTA) e o metal base (MB) por microscopia ótica e por microscopia eletrônica de varredura com EDS acoplado para análise química.

A quantificação de ferrita $\delta$ foi feita pelo método de contagem de pontos, com uma malha de 100 pontos sobreposta a micrografia com 320x de aumento. Foram utilizadas 10 micrografias de cada amostra, totalizando 1000 pontos contados para cada uma.

\section{Resultados e Discussão}

Na condição como soldado, a microestrutura do MB, Figura 1a e b, é característica do aço inox 347, consistindo de grãos austeníticos de diferentes tamanhos com a presença de precipitados no interior e contornos dos grãos [3]. Na Figura 1a são destacados os contornos de grão (i), maclas (ii), e carbetos (iii). A Figura 1 b mostra a ferrita $\delta$ dispersa na microestrutura. A ZTA, Figura 1c, apresenta aumento no tamanho de alguns grãos austeniticos e 0 aparecimento de novos grãos pequenos, característico de um mecanismo de crescimento anormal com recristalização secundária [9]. Na ZTA mais próxima à ZF, que atingiu altas temperaturas, observa-se maior teor de ferrita $\delta$ que na ZTA mais próxima ao MB. Observa-se a tendência da precipitação da ferrita $\delta$ ao longo dos contornos de grão, como indicado pelas setas na Figura $1 \mathrm{~d}$.

O teor de ferrita $\delta$ foi de $13 \%$, bem superior ao presente no MB. A influência da quantidade de ferrita $\delta$ na microestrutura dos aços está relacionada com a resistência à corrosão e as propriedades mecânicas. Na ZF,
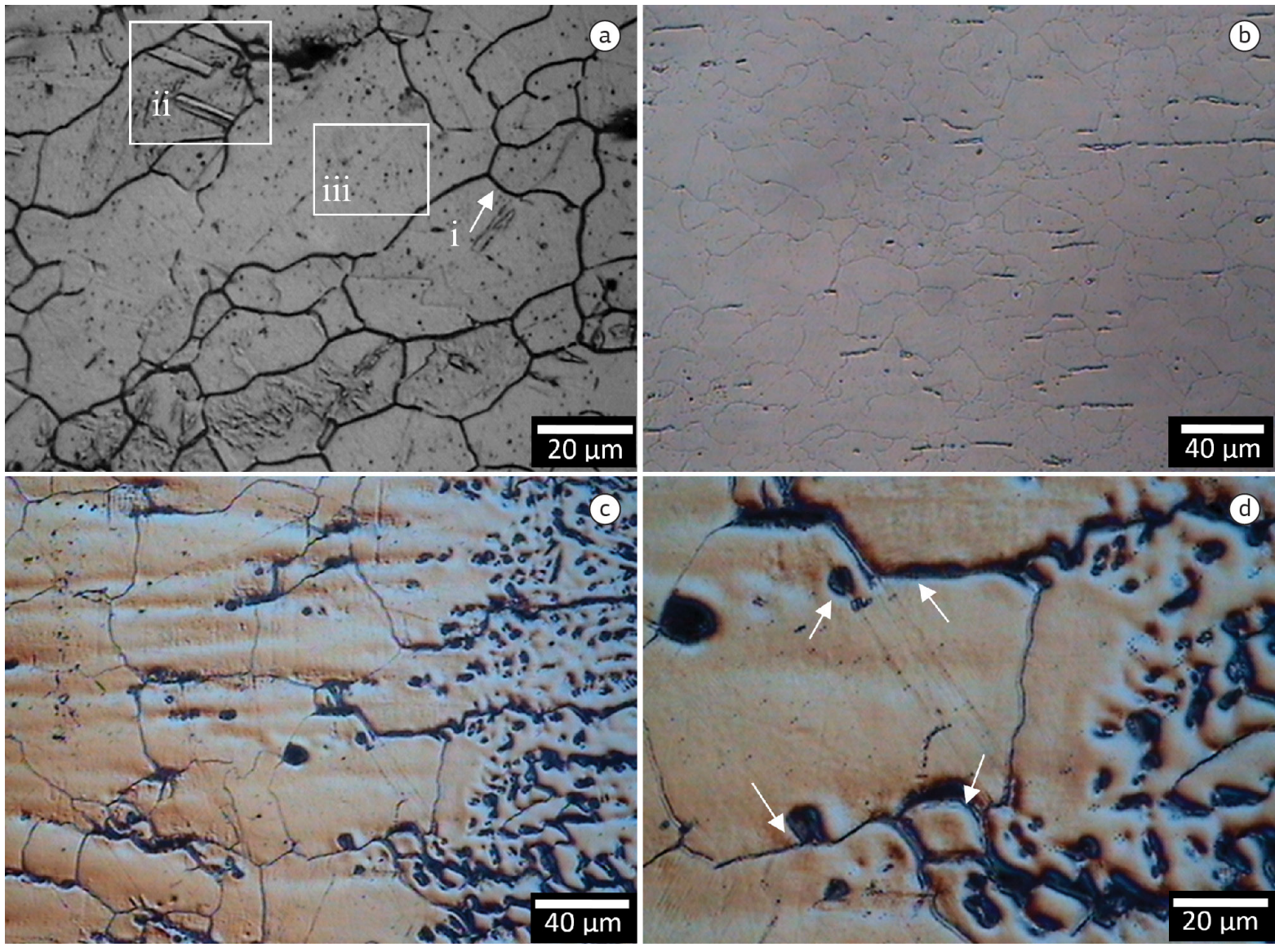

Figura 1. Condição como soldado: MB (a e b); ZTA (c e d). 
devido aos ciclos térmicos da soldagem, uma alta fração de ferrita $\delta$ foi obtida, sendo considerada prejudicial. No entanto, um mínimo de $5 \%$ de ferrita $\delta$ retida na microestrutura evita a ocorrência de trincas na solidificação em operações de soldagem [2].

A Figura 2 mostra precipitados com diferentes morfologias na ZTA. A análise por EDS identificou a presença de carbeto de $\mathrm{Nb}$, ponto 1 , carbeto de $\mathrm{Cr}$, ponto 2 e ferrita $\delta$, correspondente ao ponto 3 . Em geral os carbetos de $\mathrm{Nb}$ apresentam um tamanho menor que o da ferrita $\delta$ e maior que os carbetos de $\mathrm{Cr}$, com tendência a se precipitar na ferrita $\delta[10]$.

$\mathrm{Na}$ ZF a microestrutura consiste de uma matriz austenítica, com intensa precipitação de ferrita $\delta$ principalmente com morfologia vermicular, Figura 3a, e laminar, Figura 3b. Numa solidificação primariamente austenítica, a ferrita $\delta$ se solidifica nas regiões entre os braços das dendritas, com morfologia característica vermicular [11]. Esta tende a se apresentar de forma mais espaçada enquanto que a ferrita laminar apresenta-se com um formato mais regular, consistindo de placas paralelas (numerosas ripas).

Análise por EDS na ZF identificou precipitados semelhantes aos encontrados na ZTA, como carbeto de $\mathrm{Nb}$, ferrita $\delta$ e carbeto de Cr. A ZF mais próxima da ZTA, Figura 3c, apresenta uma diferença maior em sua microestrutura, pois a ferrita $\delta$ apresenta-se com um maior espaço entre si, sendo identificada como pequenas partículas esféricas e alongadas, Figura 3d. Comparando-se a microestrutura da ZF próxima a ZTA, Figura 3c com a do centro da ZF, Figura $3 \mathrm{e}$ e f, percebe-se que no centro da ZF ocorre maior precipitação da ferrita $\delta$ nos contornos de grão.

Condição de tratamento térmico convencional: A recomendação de tratamento térmico de solubilização após soldagem tem como objetivo dissolver parte da ferrita $\delta$ e possíveis carbetos de $C r$. Já a estabilização garante que 0 $\mathrm{Nb}$ combine-se preferencialmente ao $\mathrm{C}$ e induz a precipitação de carbetos finos de $\mathrm{NbC}$, que evitam a sensitização do material [1]. Assim, os aços inox austeníticos estabilizados ao $\mathrm{Nb}$, como o 347, podem ser utilizados em serviço em elevadas temperaturas $\left(500-800^{\circ} \mathrm{C}\right)$, devido à boa resistência à fluência da estrutura austenítica.

A microestrutura do MB, Figura 4a, é característica do aço 347 solubilizado, consistindo de grãos austeníticos de diferentes tamanhos com a presença de pequenos e esféricos precipitados no interior e contornos dos grãos. A ZTA, Figura 4b, apresenta na sua microestrutura um aumento no tamanho de alguns grãos e o aparecimento de novos grãos pequenos, característico de um mecanismo de crescimento anormal com recristalização secundária [9].

A microestrutura da ZF, Figura 4c, apresenta matriz austenítica com precipitados esféricos de ferrita $\delta$, com grãos alinhados na direção de transferência de calor e de solidificação da poça de fusão. A estrutura dendrítica decorrente da solidificação da poça de fusão na ZF na condição como soldada (Figura 3) foi homogeneizada. A ferrita $\delta$ encontrada possui morfologia esférica e/ou menos alongada e sua quantidade foi bastante reduzida, quando comparada com a condição como soldada (Figura 1). A solubilização e estabilização da ZF promoveu uma
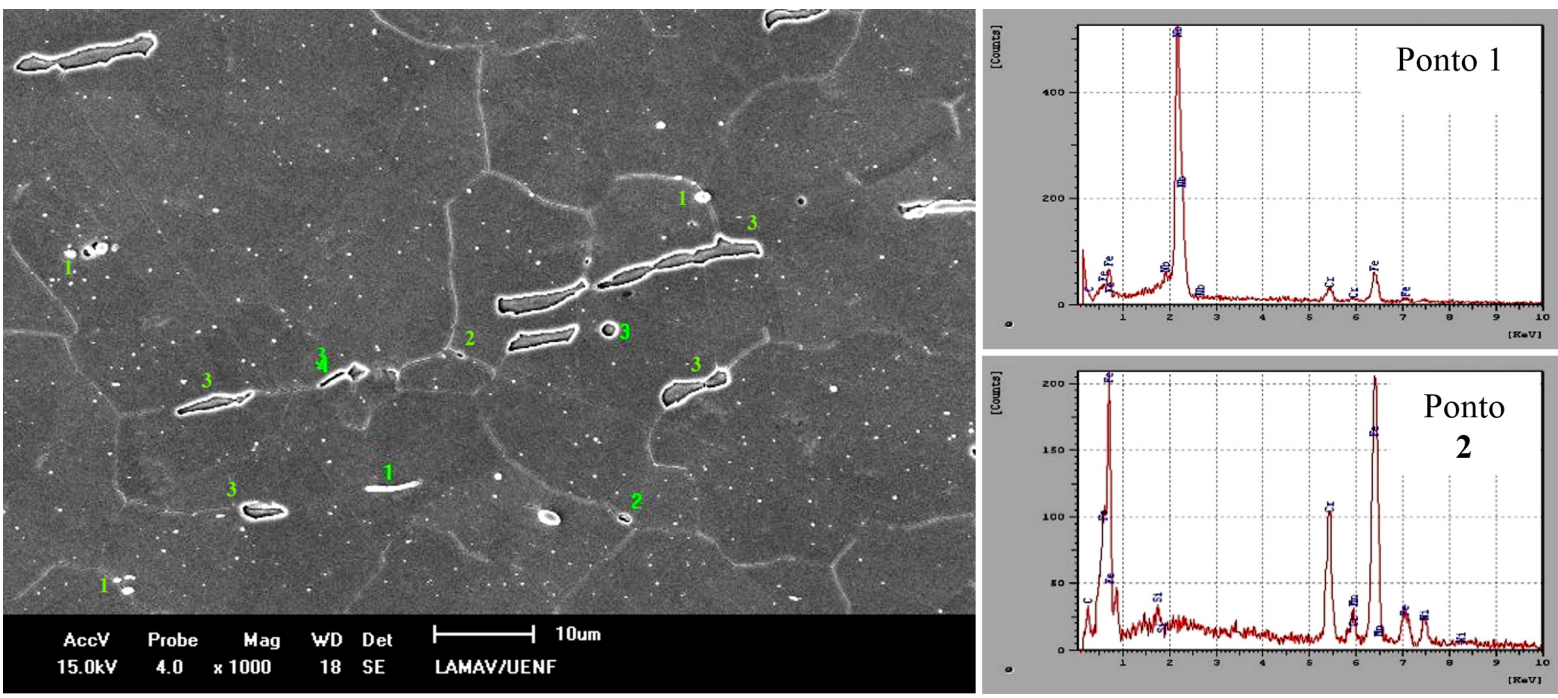

Figura 2. Condição como soldado: análise qualitativa por EDS dos precipitados indicados na ZTA. 

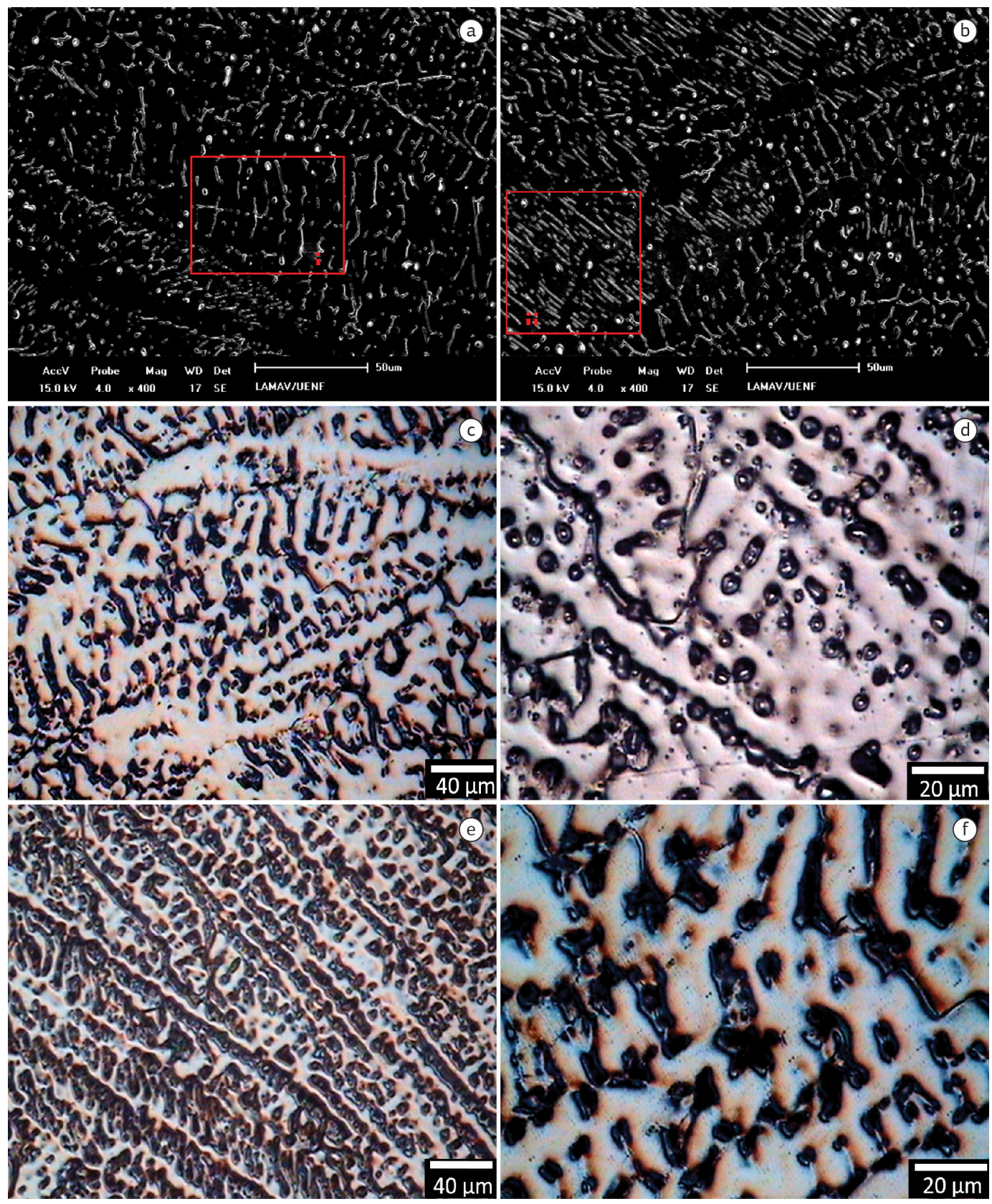

Figura 3. ZF na condição como soldado: precipitação da ferrita $\delta$ (a) com morfologia vermicular; (b) morfologia laminar; (c) e (d) ZF mais próxima da ZTA; (e) e (f) centro da ZF.

significante modificação da microestrutura em relação à condição como soldada, tornando-a mais semelhante à do $\mathrm{MB}$. $\mathrm{O}$ teor de ferrita $\delta$ na $\mathrm{ZF}$ foi de $8,9 \%$, menor que os $13 \%$ apresentado pela amostra na condição como soldado, atestando quantitativamente o que foi observado na comparação entre as microestruturas das respectivas amostras. Logo, foi observado que o tratamento térmico de solubilização promoveu uma redução da quantidade de ferrita $\delta$ na ZTA e ZF da junta na condição como soldada.

A Figura 5 mostra a microestrutura no MEV e os EDS com a composição de 3 regiões com precipitados selecionados do $\mathrm{MB}$. $\mathrm{O}$ ponto 1 nitidamente é um carbeto de $\mathrm{Nb}$, enquanto os pontos 2 e 3 provavelmente são carbetos de $\mathrm{Nb}$ e Cr. Já a ZTA, Figura 6, apresenta os mesmos tipos de precipitados que o MB: o ponto 1 indica ser um carbeto de $\mathrm{Nb}$ e $\mathrm{Cr}$, o ponto 2 refere-se à matriz austenítica, e o ponto 3 indica ser um carbeto de $\mathrm{Nb}$. Pode-se 

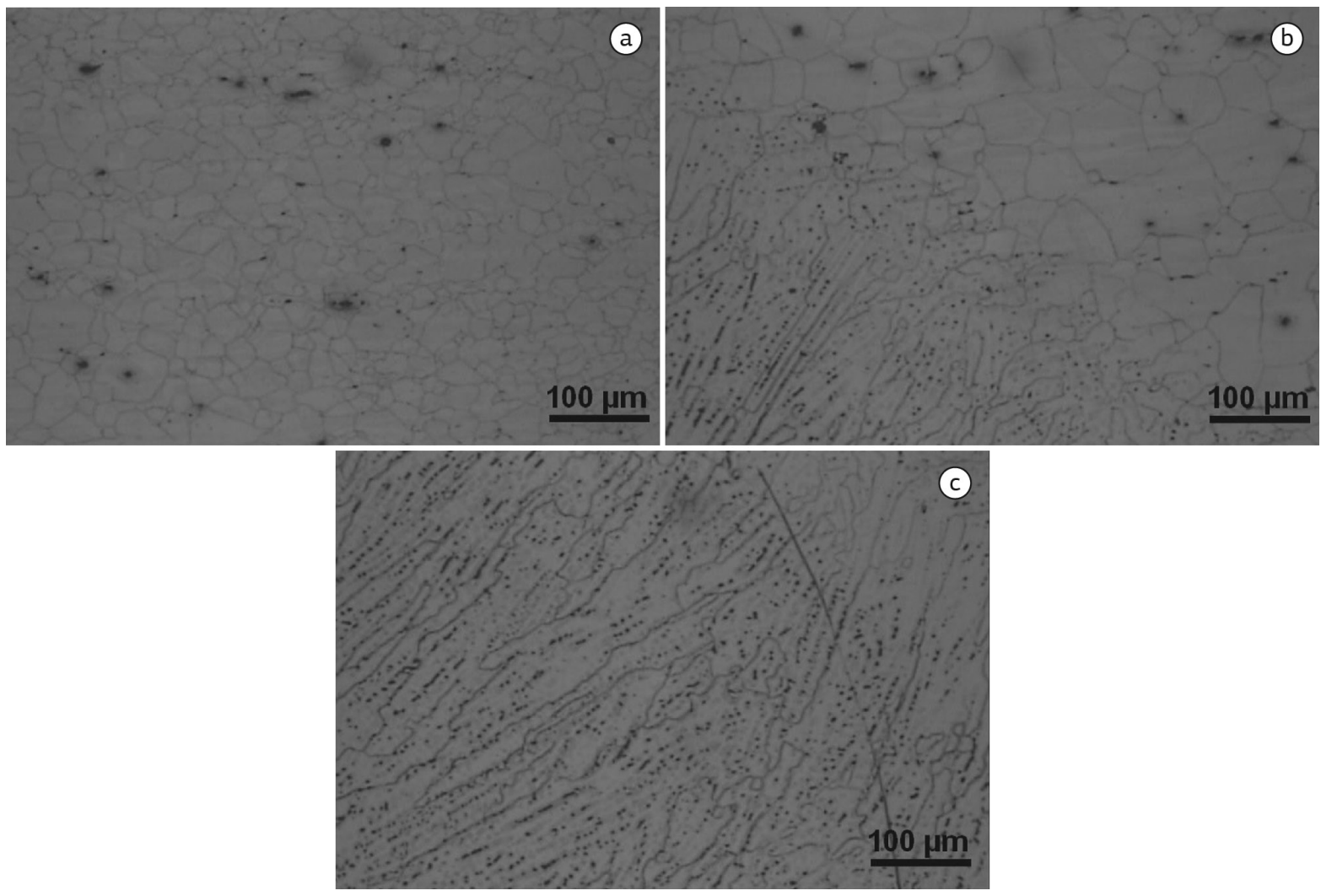

Figura 4. Microestrutura após tratamento térmico convencional de solubilização e estabilização: (a) metal base; (b) ZTA; (c) zona fundida. Aumento de 100x com Microscopia Ótica.

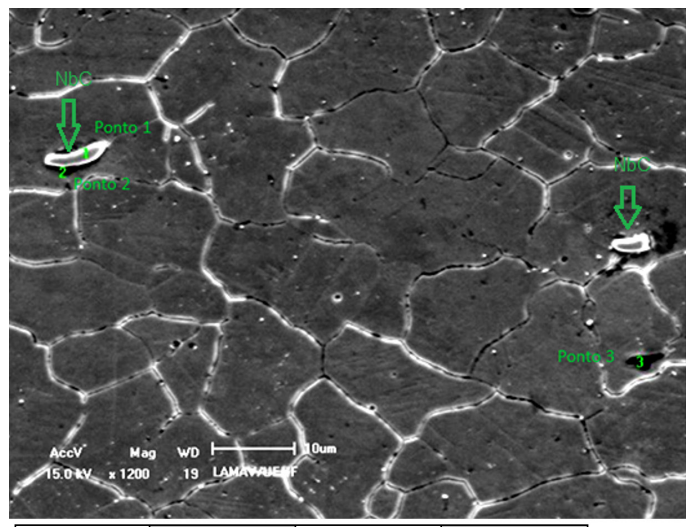

\begin{tabular}{|l|l|r|c|}
\hline & Ponto 1 & Ponto 2 & Ponto 3 \\
\hline $\mathrm{Fe}(\%)$ & ---- & 63,232 & 55,467 \\
\hline $\mathrm{Cr}(\%)$ & ---- & 14,056 & 13,341 \\
\hline $\mathrm{Ni}(\%)$ & ---- & 9,986 & 7,064 \\
\hline $\mathrm{Nb}(\%)$ & 90,263 & 2,102 & $\mathbf{0 , 8 6 6}$ \\
\hline $\mathrm{Si}(\%)$ & ---- & 1,232 & $\mathbf{0 , 7 9 0}$ \\
\hline $\mathrm{C}(\%)$ & 9,737 & 5,478 & 20,582 \\
\hline
\end{tabular}

Figura 5. Metal base do material na condição de tratamento térmico convencional: microestrutura no MEV com resultados de EDS em três pontos selecionados. 
concluir que o tratamento térmico de solubilização e estabilização convencional, como esperado, foi eficaz em promover a precipitação de carbetos ricos em $\mathrm{Nb}$, tanto no MB como na ZTA, evitando assim possível sensitização futura destas regiões.

A Figura 7 apresenta a composição de três regiões analisadas na ZF: o ponto 1 refere-se à matriz austenítica, onde nota-se um maior teor de Ní; o ponto 2, pela maior composição de $\mathrm{Cr}$, refere-se a um precipitado de ferrita $\delta$; $O$ ponto 3 apresenta composição de ferrita $\delta$ com teor de $\mathrm{Nb}$, sugerindo a presença de carbeto de $\mathrm{Nb}$ adjacente ao precipitado de ferrita $\delta$. Em geral, esses carbetos apresentam um tamanho menor que o de ferrita $\delta$, e maior que carbetos de $\mathrm{Cr}$, com tendência a se formar na ferrita $\delta[10]$.

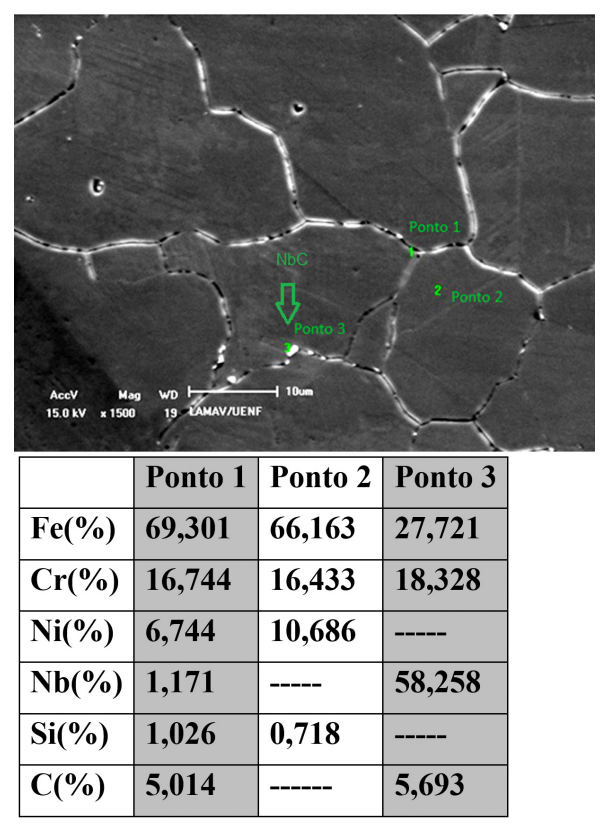

Figura 6. ZTA do material na condição de tratamento térmico convencional: microestrutura no MEV com resultados de EDS em três pontos selecionados.

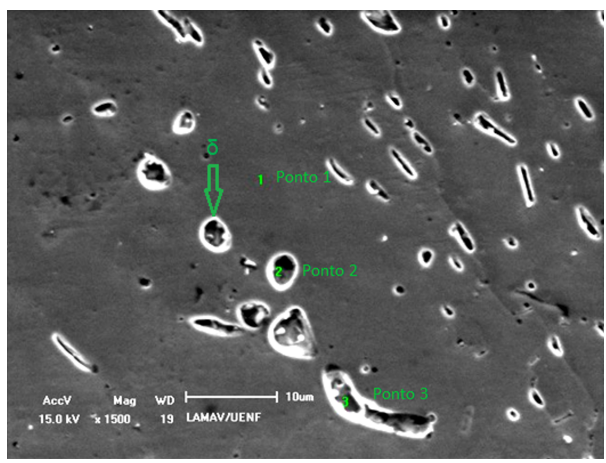

\begin{tabular}{|l|l|l|l|}
\hline & Ponto 1 & Ponto 2 & Ponto 3 \\
\hline $\mathrm{Fe}(\%)$ & 63,225 & 65,910 & 67,104 \\
\hline $\mathrm{Cr}(\%)$ & 16,824 & 27,083 & 27,460 \\
\hline $\mathrm{Ni}(\%)$ & 15,407 & 4,013 & 3,379 \\
\hline $\mathrm{Nb}(\%)$ & --- & ---- & 2,057 \\
\hline $\mathrm{Si}(\%)$ & $\mathbf{0 , 6 1 7}$ & $\mathbf{0 , 8 2 0}$ & ---- \\
\hline $\mathrm{C}(\%)$ & 3,897 & 2,174 & ---- \\
\hline
\end{tabular}

Figura 7. ZF do material na condição de tratamento térmico convencional: microestrutura no MEV com resultados de EDS para três pontos selecionados. 
A precipitação dos diversos tipos de carbetos pode ocorrer em diferentes temperaturas nos aços solubilizados expostos a temperaturas de serviço de $500-800{ }^{\circ} \mathrm{C}[1,5,7,12,13]$. Quando nessas temperaturas há primeiramente a formação de carbetos $\mathrm{Cr}_{23} \mathrm{C}_{6}$. Para que se forme primeiramente o $\mathrm{NbC}$, há de se realizar o tratamento térmico no nariz da curva de formação do $\mathrm{NbC}$, aproximadamente $900^{\circ} \mathrm{C}$ [1].

Observa-se que após o tratamento térmico convencional de solubilização e estabilização ocorreu uma redistribuição dos carbetos de $\mathrm{Nb}$, o que é desejável, pois além de reduzir a possibilidade do carbono se ligar ao $\mathrm{Cr}$, diminui os locais para precipitação de possíveis carbetos, que deixariam o material susceptível a corrosão intergranular. A precipitação de carbetos de $\mathrm{Cr}$ foi evitada.

O tratamento térmico de solubilização a $1.040^{\circ} \mathrm{C}$, antecedendo o tratamento térmico de estabilização na faixa de $850^{\circ} \mathrm{C}$ a $950^{\circ} \mathrm{C}$, é de suma importância para utilização do material em temperaturas na faixa de $450^{\circ} \mathrm{C}$ a $800^{\circ} \mathrm{C}$. A solubilização promove a redução do teor de ferrita, bem como a mudança de sua morfologia, e permite a difusão do Nióbio, causando uma melhor redistribuição deste elemento na fase austenita, melhorando a resposta ao tratamento de estabilização. Obtém-se, então, uma melhor resistência à corrosão intergranular devido a maior dispersão dos carbetos de $\mathrm{Nb}$.

Realizar o tratamento térmico de estabilização sem um tratamento prévio de solubilização pode ocasionar no aço um elevado grau de sensitização [1]. Conclui-se que, em juntas soldadas para utilização em altas temperaturas, como no caso de tubos soldados, a sequência de solubilização $\left(1.040^{\circ} \mathrm{C}\right)$ e estabilização, na faixa de $850^{\circ} \mathrm{C}$ a $950^{\circ} \mathrm{C}$, deve ser realizada para se evitar a precipitação de carbetos de $\mathrm{Cr}$ e conseqüente corrosão intergranular [1].

Condição de tratamento térmico alternativo: A microestrutura do MB é mostrada na Figura 8a, onde podem ser observados os grãos austeníticos com morfologia equiaxial, com a presença de precipitados nos contornos e no interior dos grãos. A interface da ZTA com a ZF, Figura 8b, mostra na ZTA os grãos austeníticos, que nesta condição não tiveram os contornos tão bem definidos, se apresentam com tamanho desproporcional devido ao crescimento anormal associado à recristalização secundária [9]. O aspecto da microestrutura do MB e ZTA para o tratamento térmico alternativo é bastante semelhante ao observado para o tratamento térmico convencional, Figuras 4a e b.

Na Figura 8c e d é mostrada a ZF na condição de tratamento térmico alternativo, cuja microestrutura é composta por uma matriz austenítica de grãos alongados na direção da transferência de calor da poça de solda em direção ao metal base. Há presença de ferrita $\delta$ na forma de pequenos precipitados arredondados e outros alongados. Pode-se notar que o tratamento térmico alternativo agiu de forma eficaz na solubilização da estrutura, que em sua condição como soldado (Figura 1), é composta por ferrita vermicular e laminar. A morfologia da ferrita $\delta$ foi alterada devido ao tempo de permanência em altas temperaturas, onde há maior disponibilidade de energia para elementos formadores de ferrita se difundirem e assim, serem solubilizados na matriz austenítica. Nesta condição, a morfologia da ferrita $\delta$ é bem similar, porém em menor quantidade, em relação àquela apresentada pelo material na condição de tratamento térmico convencional, Figura 4c. $O$ teor medido de ferrita $\delta$ foi de $4,5 \%$, bem menor que o da condição como soldado (13\%) e menor que o da condição de tratamento térmico convencional $(8,9 \%)$. Sabe-se que menores teores de ferrita $\delta$ reduzem a susceptibilidade à sensitização, pois favorecem a precipitação de carbetos de $\mathrm{Cr}$ no interior dos precipitados de ferrita, em vez destes se precipitarem nos contornos de grãos austeníticos [14].

A Figura 9 mostra a microestrutura no MEV e resultados de EDS para três regiões selecionadas no MB. Pode-se notar a presença de carbetos de $\mathrm{Nb}$, ponto 1 , o que se acredita ser um carbeto de $\mathrm{Nb}$ e $\mathrm{Cr}$, ponto 2, enquanto o ponto 3 corresponde a matriz austenítica. A região da ZTA, Figura 10, pode-se notar a presença de carbeto de $\mathrm{Nb}$ e $\mathrm{Cr}$ nos contornos de grão austeníticos, ponto 2 , enquanto os pontos 1 e 3 correspondem a matriz austenítica.

A Figura 11 mostra a microestrutura no MEV e resultados de EDS para a ZF, podendo-se notar que os pontos 1 e 3 correspondem a carbetos de $\mathrm{Nb}$ e $\mathrm{Cr}$, enquanto o ponto 2 corresponde a matriz austenítica. Esses carbetos se formam em volta da ferrita $\delta$ [10], em forma de filme englobando os precipitados de ferrita (ponto 1).

Os resultados acima mostram que o tratamento térmico alternativo foi eficaz em relação à formação de carbetos estabilizantes de $\mathrm{Nb}$ e na redução da quantidade de ferrita $\delta$. Na condição de tratamento térmico alternativo, a junta soldada permaneceu por mais tempo em elevadas temperaturas, possibilitando uma maior difusão de elementos solutos, reduzindo ainda mais o teor de ferrita $\delta$ em relação ao tratamento térmico convencional, levando a uma melhor distribuição desses elementos na matriz austenítica. Consequentemente, a disposição de carbetos de $\mathrm{Nb}$ foi mais uniforme, devido ao maior tempo de difusão do $\mathrm{Nb}$ na microestrutura. 

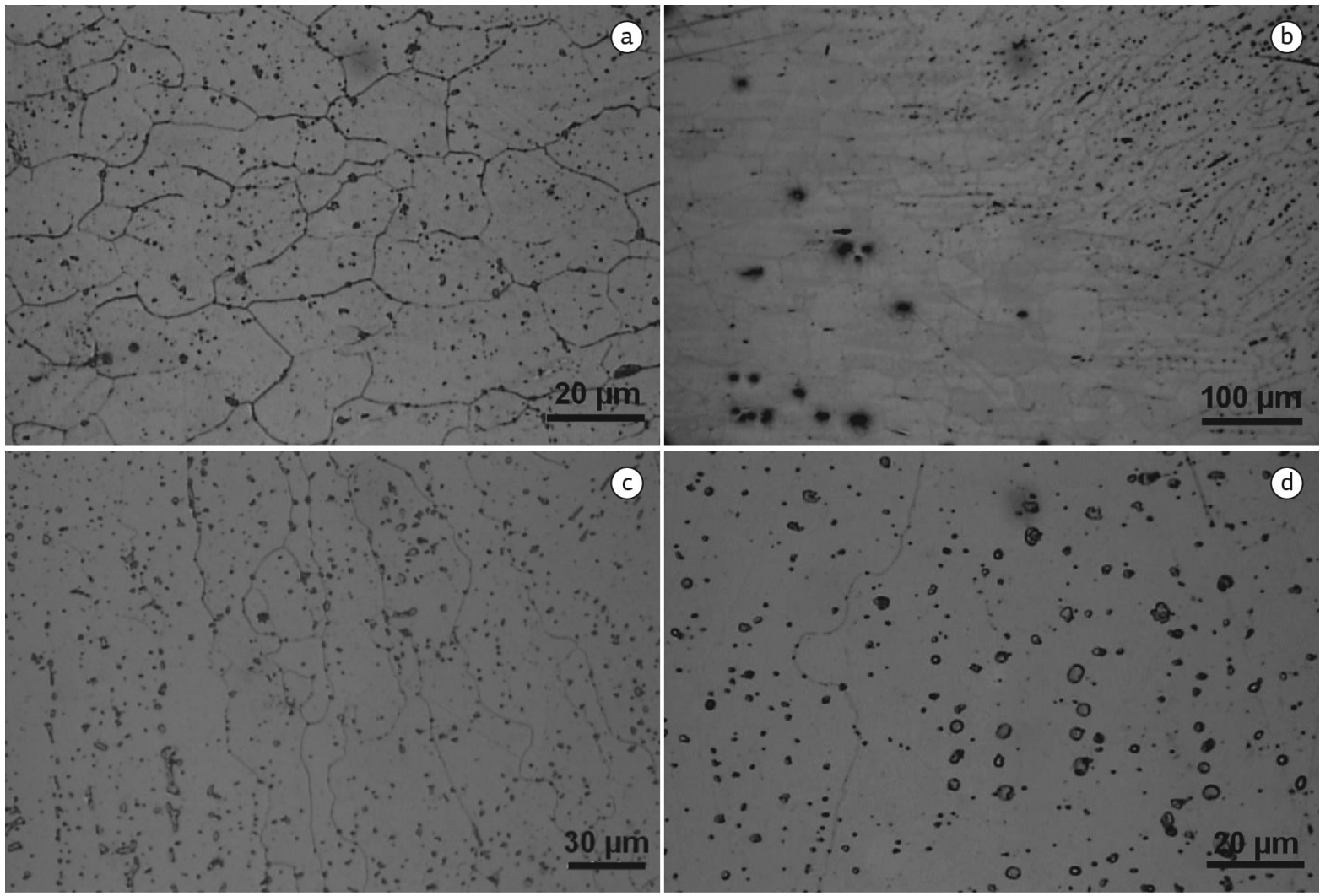

Figura 8. Material na condição de tratamento térmico alternativo (a) MB, 500x; (b) ZTA, 100x; (c) e (d) ZF, 320x e 500x, respectivamente.

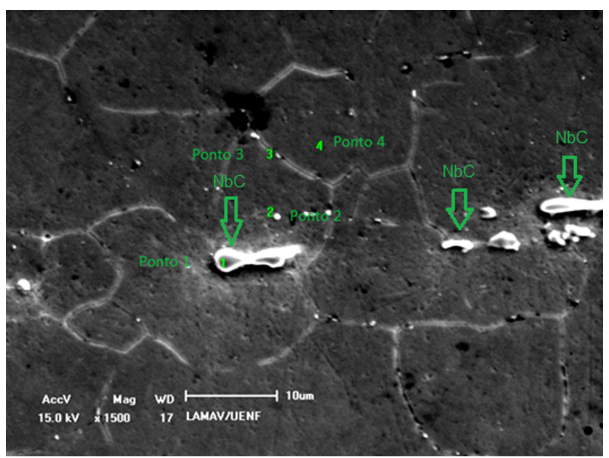

\begin{tabular}{|l|l|l|l|}
\hline & Ponto 1 & Ponto 2 & Ponto 3 \\
\hline Fe(\%) & ---- & 65,435 & 58,886 \\
\hline $\mathrm{Cr}(\%)$ & ---- & 17,279 & 15,453 \\
\hline $\mathrm{Ni}(\%)$ & --- & 8,513 & 7,930 \\
\hline $\mathrm{Nb}(\%)$ & 92,829 & 4,763 & ---- \\
\hline $\mathrm{Si}(\%)$ & 1,093 & --- & 0,853 \\
\hline $\mathrm{C}(\%)$ & $\mathbf{6 , 0 9 3}$ & $\mathbf{4 , 0 1 0}$ & --- \\
\hline
\end{tabular}

Figura 9. Metal base do material na condição de tratamento térmico alternativo: microestrutura no MEV com resultados de EDS para três pontos selecionados. 


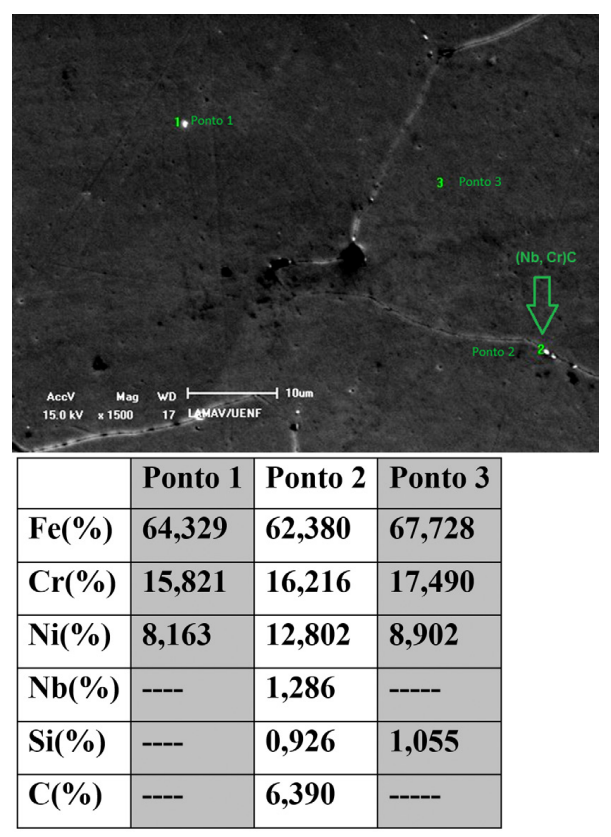

Figura 10. ZTA do material na condição de tratamento térmico alternativo: microestrutura no MEV com resultados de EDS para três pontos selecionados.

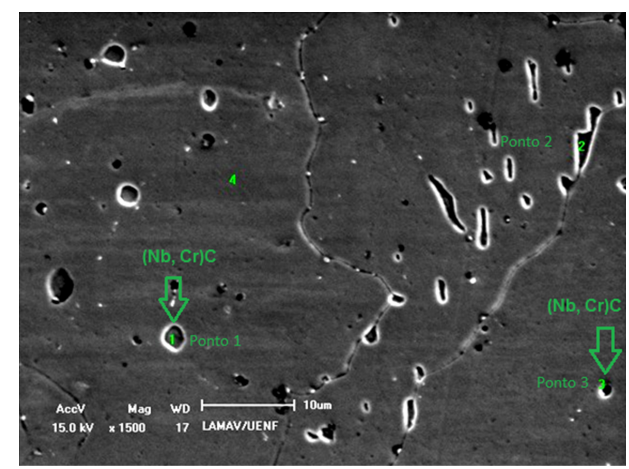

\begin{tabular}{|l|l|l|l|}
\hline & Ponto 1 & Ponto 2 & Ponto 3 \\
\hline Fe(\%) & 65,350 & 61,354 & 61,146 \\
\hline Cr(\%) & 26,855 & 23,001 & 20,527 \\
\hline Ni(\%) & ---- & 6,281 & 7,083 \\
\hline Nb(\%) & 2,228 & ---- & 5,456 \\
\hline Si(\%) & 1,124 & 1,010 & 0,063 \\
\hline C(\%) & 4,443 & ----- & 4,825 \\
\hline
\end{tabular}

Figura 11. ZF do material na condição de tratamento térmico alternativo: microestrutura no MEV com resultados de EDS para três pontos selecionados.

Como pode ser observado nos resultados de EDS para a ZF (Figura 11), os carbetos de Nb precipitam-se preferencialmente adjacentes aos precipitados de ferrita $\delta$. $O$ que em tese, tornaria a dispersão desses carbetos mais homogênea na condição de tratamento térmico alternativo, já que o teor de ferrita $\delta$ é menor nessa condição.

$\mathrm{Na}$ condição de tratamento térmico alternativo, a junta soldada foi submetida à temperatura inicial de tratamento de estabilização superior a $900^{\circ} \mathrm{C}$, temperatura superior àquela relativa ao nariz da curva de precipitação do $\mathrm{NbC}$ e de formação de outros carbetos $[1,5,7,12,13]$. Uma vez que esses carbetos são estáveis a temperaturas mais 
elevadas que a faixa de temperatura em que são utilizados esses materiais, os carbetos de $\mathrm{Nb}$ evitam a precipitação de carbetos de $\mathrm{Cr}$, evitando que ocorra a sensitização e a consequente corrosão intergranular [7].

Menores precipitados de ferrita $\delta$ favorecem a precipitação de carbetos de $\mathrm{Cr}$ no seu interior [14] e ainda, carbetos de $\mathrm{Nb}$ precipitam-se como filme englobando os precipitados de ferrita $\delta$ [10]. Como nessa condição de tratamento térmico alternativo os precipitados de ferrita $\delta$ estão bem dispersos e pequenos, os carbetos de $\mathrm{Nb}$ reduzem a quantidade de $C$ nas regiões mais suscetíveis à sensitização: os precipitados de ferrita $\delta$, em maior quantidade na ZF. Já que são essas as regiões (precipitados de ferrita $\delta$ ) com maior teor de $\mathrm{Cr}$, a presença de carbetos de $\mathrm{Nb}$ asseguraria um baixo teor de $\mathrm{C}$ nas regiões críticas para a sensitização.

Essa dispersão mais homogênea dos carbetos de $\mathrm{Nb}$ e menores precipitados de ferrita $\delta$ são indícios que o material apresente uma adequada resistência à corrosão, quando comparada a um material com carbetos de $\mathrm{Nb}$ menos dispersos, como no caso do tratamento térmico convencional.

Em estudo realizado por Terra [15] em junta soldada com o AISI 347 nas duas mesmas condições de tratamentos térmicos propostas nesse trabalho, a convencional e a alternativa, foram submetidas à avaliação de resistência à corrosão intergranular de acordo com a norma ASTM 262 [16] prática E. As amostras nas duas condições se comportaram de forma satisfatória, indicando a eficácia do tratamento térmico alternativo de solubilização e estabilização proposto neste trabalho.

O presente trabalho tem como objetivo a análise da microestrutura do aço inoxidável austenítico AISI 347 em três condições distintas: condição como soldado; condição de tratamento térmico convencional de solubilização e estabilização de acordo com a norma ASTM 358 [8]; e condição de tratamento térmico alternativo, consistindo na realização da solubilização seguida da estabilização sem saída do forno.

A microestrutura apresentada pelo material na condição de tratamento térmico convencional é característica desse tipo de condição, tendo uma redução significativa do teor de ferrita $\delta$ e de carbetos de $\mathrm{Cr}$ relativamente à condição como soldado. Isso se deve ao tratamento térmico de solubilização, que permite a difusão dos elementos solutos para a matriz austenítica, dissolvendo a ferrita $\delta$ e precipitados provenientes do ciclo térmico de soldagem. Após a estabilização, a microestrutura da junta soldada apresentou carbetos de $\mathrm{Nb}$, responsáveis pela resistência a corrosão intergranular relacionada à sensitização.

A condição de tratamento térmico alternativo apresentou microestrutura muito similar à da condição de tratamento térmico convencional. A solubilização foi eficaz na dissolução de elementos formadores de ferrita $\delta$, cujo teor foi ainda menor que o obtido na condição de tratamento térmico previsto por norma. Também teve em sua microestrutura a presença de carbetos de $\mathrm{Nb}$, constituinte responsável pela resistência à corrosão intergranular [7], sugerindo eficácia do tratamento térmico de estabilização.

A norma ASTM 358 [8] determina que após a solubilização o aço em questão deve ser resfriado rapidamente em água ou por outros meios, e prevê que para os aços estabilizados $(321,321 \mathrm{H}, 347,347 \mathrm{H}$ e 348$)$ deve ser realizado o tratamento térmico de estabilização. Como é previsto por norma o resfriamento do aço após a solubilização, há queda de temperatura do forno, necessitando do aquecimento dele para a realização da estabilização. Enquanto que no tratamento térmico alternativo não há resfriamento do aço até a temperatura ambiente, apenas redução da temperatura do forno até o patamar da estabilização e realização deste.

$\mathrm{O}$ tratamento térmico realizado de forma alternativa àquela prevista por norma apresenta uma série de vantagens: redução do tempo total do tratamento, tendo em vista a necessidade do resfriamento à temperatura ambiente após a solubilização e o posterior aquecimento da peça no forno por uma segunda vez para a estabilização; redução do consumo de energia, pois não há necessidade de se aquecer o forno pela segunda vez, apenas reduz-se a temperatura até o patamar da estabilização;

Logo, os resultados aqui apresentados justificam a rota de tratamento térmico alternativo proposto para as juntas soldadas com o aço AISI 347. Há vantagens que poderiam reduzir o custo de produção, tornando esse produto mais barato, consequentemente, mais competitivo. Os dados aqui obtidos relativos à análise microestrutural, de EDS, e de quantificação de ferrita delta, em conjunto com os resultados obtidos por Terra [15], podem ser úteis como embasamento para uma possível alteração da norma ASTM 358 [8], que regula a produção de tubos soldados do aço em questão. Alteração que acarretaria na diminuição dos custos de fabricação e do tempo necessário para produção deste tipo de peça. 


\section{Conclusões}

Da avaliação da microestrutura de uma junta soldada no aço AISI 347, estudando o efeito dos tratamentos térmicos de solubilização e estabilização, realizados de forma convencional em etapas distintas, ou de forma alternativa com apenas uma passagem dentro do forno, pode-se concluir que:

- Na condição como soldada, a ZTA apresenta matriz austenitica com grãos poligonais, com tamanho desproporcional devido à recristalização secundária. A ZF apresenta uma matriz de grãos austeníticos que se alinham na direção de transferência do calor, com $13 \%$ de ferrita $\delta$ nas morfologias vermicular e laminar;

- Após tratamento térmico convencional de solubilização e estabilização, a microestrutura na ZTA é composta da matriz de grãos austeníticos e a presença de carbetos de $\mathrm{Nb}$ e $\mathrm{Nb}$ e $\mathrm{Cr}$. Na ZF o aspecto da matriz austenitica assemelha-se ao do $\mathrm{MB}$, o teor de ferrita $\delta$ foi reduzido para 8,9\% e observa-se a presença de carbetos de $\mathrm{Nb}$ e $\mathrm{Nb}$ e $\mathrm{Cr}$, sugerindo a eficácia dos tratamentos térmicos convencionais de solubilização e de estabilização;

- Após tratamento térmico alternativo de solubilização e estabilização, a microestrutura da ZTA e ZF foi similar à obtida no tratamento convencional, sendo que o teor de ferrita $\delta$ na ZF foi ainda mais reduzido, de 4,5\%;

- O tratamento térmico alternativo de solubilização e estabilização foi considerado ser tão eficaz quanto o tratamento térmico convencional para a adequação da microestrutura da junta soldada, com uma significativa vantagem do tratamento térmico proposto em reduzir o tempo e o custo desta operação.

\section{Referências}

[1] Kina AY, Souza VM, Tavares SSM, Souza JA, de Abreu HFG. Influence of heat treatments on the intergranular corrosion resistance of the AISI 347 cast and weld metal for high temperature services. Journal of Materials Processing Technology. 2008;199(1-3):391395. http://dx.doi.org/10.1016/j.jmatprotec.2007.08.011.

[2] Gill TPS, Shankar V, Pujar MG, Rodriguez P. Effect of composition on the transformation of $\delta$-ferrite to $\sigma$ in type 316 stainless steel weld metals. Scripta Metallurgica et Materialia. 1995;32(10):15951600. http://dx.doi.org/10.1016/0956-716X(95)00242-N.

[3] Terada M, Saiki M, Costa I, Padilha AF. Microstructure and intergranular corrosion of the austenitic stainless steel 1.4970. Journal of Nuclear Materials. 2006;358(1):40-46. http://dx.doi. org/10.1016/j.jnucmat.2006.06.010.

[4] Sasikala G, Mathew MD, Bhanu Sankara Rao K, Mannan SL. Creep deformation and fracture behaviour of a nitrogenbearing type 316 stainless steel weld metal. Journal of Nuclear Materials. 1999;273(3):257-264. http://dx.doi.org/10.1016/ S0022-3115(99)00057-4.

[5] Moura V, Kina AY, Tavares SSM, Lima LD, Mainier FB. Influence of stabilization heat treatments on microstructure, hardness and intergranular corrosion resistance of the AISI 321 stainless steel. Journal of Materials Science. 2008;43(2):536-540. http:// dx.doi.org/10.1007/s10853-007-1785-5.

[6] Ritoni M, Mei PR, Martins M. Efeito do tratamento térmico de solubilização na microestrutura e nas propriedades de impacto do aço inoxidável superaustenítico ASTM A 744 Gr. CN3MN. Revista Escola de Minas. 2010;63(1):13-20. http:// dx.doi.org/10.1590/S0370-44672010000100003.

[7] Vach M, Kuníková T, Domanková M, Sevc P, Caplovic L, Gogola $P$, et al. Evolution of secondary phases in austenitic stainless steels during longterm exposures at 600,650 and $800^{\circ} \mathrm{C}$. Materials Characterization. 2008;59(12):1792-1798. http:// dx.doi.org/10.1016/j.matchar.2008.04.009.

[8] ASTM International. ASTM A358/A358M - 12: Standard specification for electric-fusion-welded austenitic chromium- nickel stainless steel pipe for high-temperature service and general applications. West Conshohocken: ASTM International; 2013.

[9] $\mathrm{Hu} \mathrm{H}$. Recovery, recrystallization and grain-growth structures. In: Vander Voort GF. ASM Handbook, Volume 9: Metallography and Microestruture. Materials Park: ASM International; 1998. p. 692-699.

[10] Yoon JH, Yoon EP, Lee BS. Correlation of chemistry, microstructure and ductile fracture behaviours of niobium-stabilized austenitic stainless steel at elevated temperature. Scripta Materialia. 2007;57(1):25-28. http://dx.doi.org/10.1016/j. scriptamat.2007.03.025.

[11] Brooks JA, Thompson AW. Microstructural development and solidification cracking susceptibility of austenitic stainless steel welds. International Materials Reviews. 1991;36(1):16-44. http://dx.doi.org/10.1179/imr.1991.36.1.16.

[12] Lo KH, Shek CH, Lai JKL. Recent Developments in Stainless Steels. Materials Science and Engineering R Reports. 2009;65(4-6):39104. http://dx.doi.org/10.1016/j.mser.2009.03.001.

[13] Tavares SS, Souza VM, Souza JA, Kina AY. Influência dos tratamentos térmicos de estabilização e solubilização na resistência à corrosão intergranular do aço inoxidável AISI 347 fundido. Tecnologia em Metalurgia e Materiais. 2008;4(3):1822. http://dx.doi.org/10.4322/tmm.00403004.

[14] David SA, Vitek JM, Alexander DJ. Embrittlement of austenitic stainless steel welds. Journal of Nondestructive Evaluation. 1996;15(3-4):129-136. http://dx.doi.org/10.1007/BF00732040.

[15] Terra RF. Estudo da influência dos tratamentos térmicos de solubilização e estabilização em junta soldada de aço inoxidável austenítico 347 (AISI 347) [projeto final de graduação]. Campos dos Goytacazes: Laboratório de Materiais Avançados, Universidade Estadual do Norte Fluminense Darcy Ribeiro; 2013.

[16] ASTM International. ASTM A262-13: Standard practices for detecting susceptibility to intergranular attack in austenitic stainless steels. West Conshohocke: ASTM International; 2013. 